SGientia studia, São Paulo, v. 6, n. 4, p. 639-54, 2008

\title{
sit \\ Sobre o Tratado de mecânica de Descartes
}

\author{
Marisa Carneiro de Oliveira Franco Donatelli
}

O pensamento de Descartes caracteriza-se pela defesa da unidade de conhecimento que indica a relação estreita existente entre as ciências a partir de uma fundamentação metafísica. Nesse quadro, a mecânica ocupa um lugar ao lado da medicina e da moral como resultados que podem ser colhidos dessa concepção unificadora. Assim, lembrando de certa maneira Francis Bacon, Descartes, no Discurso sobre o método, promove a união entre as artes mecânicas e a filosofia: a defesa de uma filosofia que tenha utilidade para o homem:

no lugar dessa filosofia que se ensina nas escolas, pode-se encontrar uma prática pela qual, conhecendo a força e as ações do fogo, da água, do ar, dos astros, dos céus e de todos os outros corpos que nos cercam tão distintamente como conhecemos os diversos trabalhos de nossos artífices, poderíamos empregá-los da mesma maneira a todos os usos para os quais eles são adequados e assim nos tornarmos como mestres e possuidores da natureza (AT, 6, p. 61-2).

Essa atenção devotada à mecânica acompanha o filósofo desde o início de seus estudos; pode ser constatado nos registros que compõem as Cogitationes privatx, nas quais se encontra uma referência aos autômatos, seja na forma de equilibrista, seja na da pomba de Arquitas de Tarento (cf. AT, 10, p. 231-2).

O primeiro texto de Descartes que contém uma explicação das máquinas data do período de publicação do Discurso do método e encontra-se na correspondência entre Descartes e Huygens do ano de 1637. Esse texto, cuja tradução publicamos a seguir, foi depois denominado Tratado de mecânica por Nicolas-Joseph Poisson, que o publicou em 1668, juntando um valioso comentário, denominado "Observações sobre as mecânicas do Sr. Descartes”, no qual apresenta a explicação das máquinas que empregam pouca força para levantar grandes pesos. 
Em carta de 8 de setembro de 1637 , Huygens pede a Descartes a composição de um pequeno tratado sobre os fundamentos da mecânica com exemplos de alguns instrumentos nos quais os fundamentos pudesse ser ilustrados, chegando a mencionar a polia e a alavanca. Esse pedido é justificado pela ausência de tratados de mecânica que apresentem uma explicação objetiva e clara. Nesse sentido, é feita a referência aos textos de Guidobaldo e de Galileu:

Vi, há algum tempo, o que Guidobaldo escreveu e, mais tarde, Galileu, traduzido por Mersenne, mas um e outro pouco satisfazem, e chego a imaginar que essas pessoas apenas envolvem com superfluidades obscuras uma coisa que, tenho certeza, vós compreendereis em duas ou três posições, nada havendo ali, do meu ponto de vista, que se compreenda de uma forma clara e necessária (AT, 1, p. 397).

Em outubro, Huygens tem seu pedido atendido com o envio de uma carta acompanhada de uma explicação que contempla a descrição de cinco máquinas - com desenhos feitos por Descartes - e que se vale de um princípio básico. Essa carta, de 5 de outubro de 1637 , remete a uma preocupação concernente ao polimento das lentes, mais especificamente das lentes hiperbólicas, que acompanha Descartes desde 1629. ${ }^{1}$

A explicação das máquinas compõe um pequeno texto que, por causa dessa brevidade, deixa de lado alguns pontos, como afirma posteriormente o próprio autor em carta de 25 de janeiro de1638, tais como "a consideração da velocidade, as dificuldades da balança e muitos meios dos quais é possível valer-se para aumentar a força dos movimentos que diferem dos que eu expliquei" (AT, 1, p. 506). Assim, o tratado de mecânica, por sua datação, pode ser considerado como uma extensão dos ensaios que acompanham o Discurso do método e está inserido na concepção da filosofia prática de Descartes, tão bem expressa na sexta parte do Discurso do método.

O princípio, que está na base da construção de todos os instrumentos apresentados no tratado, consiste na assunção de que a mesma força necessária para levantar um peso "de 100 libras a uma altura de dois pés pode levantar um peso de 200 libras a uma altura de um pé ou um de 4,00 libras a uma altura de meio pé" (AT, 1, p.4.35-6). Enfim, a mesma força ${ }^{2}$ requerida para levantar um determinado peso a certa altura, pode levantar o dobro desse peso à metade dessa altura. Trata-se de um trabalho teórico sobre

1 Para esse fim, Descartes propôs a construção de uma máquina a Ferrier (AT, 1, p. 32-52). Na Dióptrica (1637), encontra-se uma ilustração dessa máquina no discurso intitulado "Sobre a forma de cortar os vidros" (AT, 6, p. 218). 2 Força é entendida como ação, como esforço por parte do homem, por parte de um peso ou de uma engrenagem (cf. Carta a Mersenne de 15.11.1638, AT, 2, p. 4,32-3). Trata-se da nomenclatura utilizada por Descartes para o que passou a ser chamado posteriormente de trabalho (cf. Duhem, 1991, p. 226-4,3). 


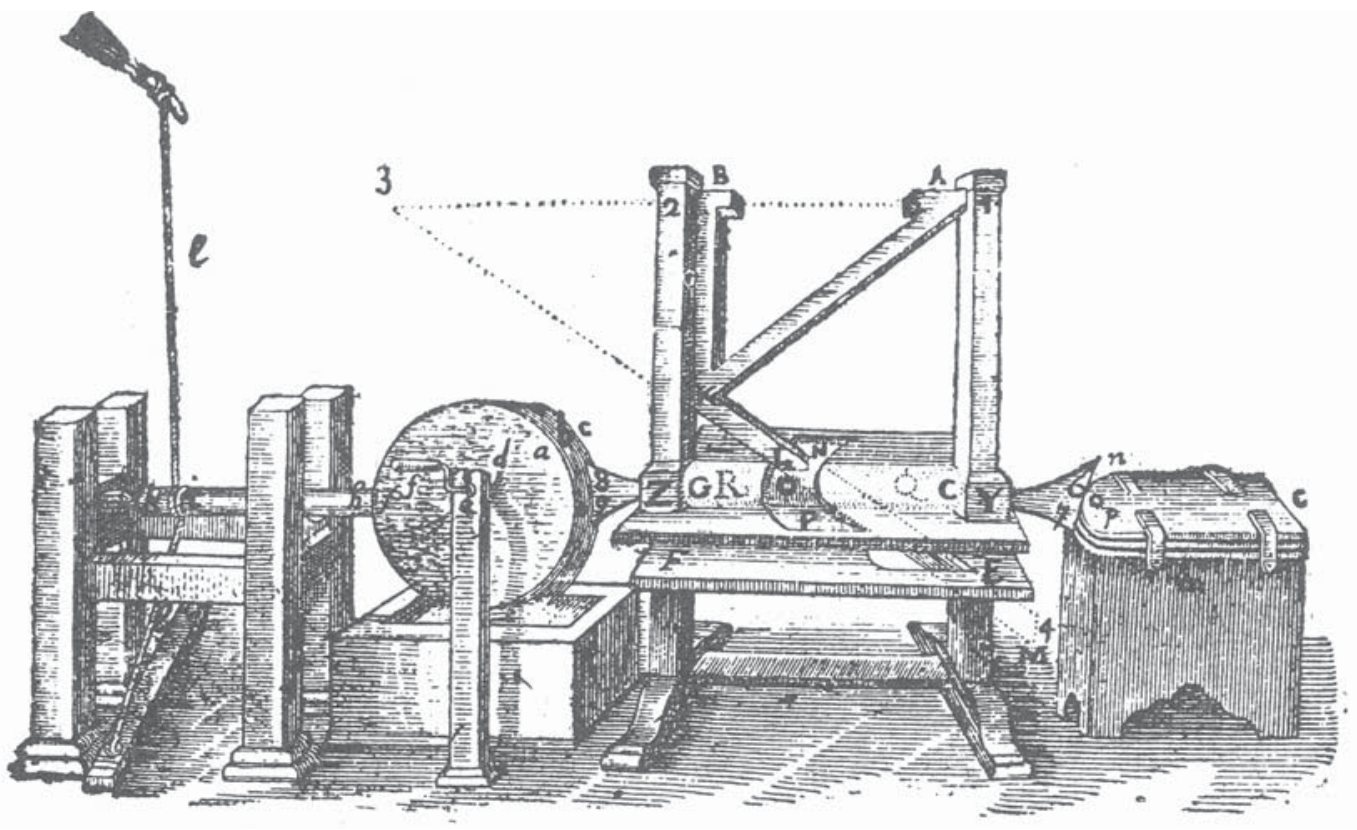

Figura 1. Ilustração que se encontra na Dióptrica $\left({ }_{163}\right.$ ) da máquina para polimento das lentes hiperbólicas, cuja construção Descartes propôs a Ferrier em 1629.

estática que toma como base o princípio de equivalência para levantar pesos, que considera apenas a força e o deslocamento: o efeito deve ser sempre proporcional à ação que é necessária para produzi-la. Ao final da explicação, Descartes aponta para a limitação desse seu texto, com respeito ao que lhe foi pedido, pois, como afirma, "há uma infinidade de outras coisas a serem consideradas nas mecânicas, a respeito das quais nada digo" (AT, 1, p. 447).

É interessante notar que, em 15 de fevereiro de 1638, Descartes envia a Plempius uma explicação da pulsação arterial, tomando por base, como afirma, "as leis da minha mecânica, isto é da física" (AT, 1, p. 524). O filósofo elabora uma explicação mecanicista do batimento cardíaco que não recebe adesão por parte de Plempius, especificamente quanto à fermentação do sangue que é considerada como invenção. Plempius, ainda preso à tradição, defende a existência de uma faculdade pulsátil como causa do movimento do coração. A explicação cartesiana do corpo, considerado como máquina, ne- 
cessita de um motor que possibilite todas as funções fisiológicas, e esse motor encontra-se no fogo cardíaco que, por um processo semelhante à fermentação, faz que o sangue entre em ebulição e distribua-se pelo corpo por meio das artérias. É dessa forma que Descartes constrói sua explicação do batimento cardíaco, ou seja, com sustentação nas leis mecânicas. As leis consideradas aqui são as que se encontram no tratado O mundo, ou seja, as leis do movimento que reaparecerão na segunda parte (art. $3 \eta_{-42}$ ) dos Princípios da filosofia, que trata dos princípios das coisas materiais e que estão na base da mecânica moderna. Nesses textos, não há menção, em nenhuma passagem, ao princípio invocado por Descartes para a construção das máquinas.

Em março de 1638, Descartes apresenta, desta vez a Huygens, uma variação dessa vinculação entre a mecânica e a física, ao atrelar as mecânicas às leis da natureza, tal como estão expostas no tratado $O$ mundo, ainda inédito, uma vez que elas "dependem (...) principalmente daquilo que diz respeito à velocidade do movimento" (AT, 2, p. 50). Assim, nota-se que, em um primeiro momento, Descartes refere-se à mecânica quando a vincula à física e ao corpo teórico; e refere-se às mecânicas quando as vincula às leis da natureza. A explicação e a delimitação das leis da natureza, bem como a ação ordinária da natureza são fundamentais para que se possa passar, em seguida, a sua aplicação e, consequentemente, chegar às mecânicas, ou seja, à teoria das máquinas, conforme o desejo de Huygens.

Em 13 julho de 1638 , Descartes envia a Mersenne ${ }^{3}$ uma versão reduzida de sua explicação e volta-se para a questão geostática, por meio de três exemplos que estão presentes no texto enviado a Huygens: a polia, o plano inclinado e a alavanca, tomando como base

um só princípio que é o fundamento geral de toda a estática, a saber, não é preciso nem mais nem menos força para erguer um corpo a certa altura do que para erguer outro menos pesado a uma altura tanto maior quanto menos pesado é, ou para erguer um mais pesado a uma altura, na mesma proporção (AT, 2, p.228).

$\mathrm{Na}$ continuação desse texto, Descartes repete o enunciado que inaugura a explicação das máquinas enviada a Huygens no ano anterior. Esta última carta é referida por Descartes em setembro (AT, 2, p. 355) como sendo um "pequeno escrito de estática”. Descartes tem a intenção de desfazer um mal entendido referente ao princípio considerado no exame da geostática, na carta de 13 de julho de 1638 . Ele afirma como

3 É Importante lembrar que a correspondência com Mersenne também contempla questões concernentes à mecânica. Além dessa carta, pode ser mencionado o fato de Mersenne ter traduzido para o latim fragmentos desse tratado que foram inseridos em seus Cogitata physico-mathematica (Cogitações físico-matemáticas) (1644). 
fundamental compreender que a força utilizada para erguer um peso a qualquer altura tem sempre duas dimensões (variáveis), enquanto que a que serve para sustentá-lo em cada ponto tem uma dimensão. Uma dificuldade apontada como responsável pela má compreensão do princípio diz respeito à confusão entre espaço, tempo e velocidade (AT, 2, p. 353), sendo que apenas o primeiro deve ser levado em consideração, pois a força aí considerada tem sempre duas dimensões: peso e distância. Na explicação da variação existente na proporção entre força e resistência, deve ser considerada a proporção entre os deslocamentos. A velocidade e o tempo, no que diz respeito à abordagem cartesiana em estática, podem ser dispensados, uma vez que a geometria consegue compor as explicações por meio da representação, posto que, nesse âmbito, não há necessidade de considerar a influência do ambiente sobre os corpos (cf. Kobayashi, 1996, p. 114). Para compreender com propriedade o que é velocidade, segundo Descartes, é preciso explicar "o que é gravidade (peso) 4 e junto todo o sistema do mundo" (AT, 2, p. 355).

Ao considerar o universo como pleno, Descartes preenche o espaço com três tipos de elementos ${ }^{5}$ que interagem de tal forma que o movimento das partículas da matéria provoca alterações em todo o entorno, produzindo as diferentes disposições dos corpos. As partículas que compõem a matéria sutil, que está na base da composição dos céus, são dotadas de intensa agitação e, ao entrarem em choque com as partículas de matéria do terceiro elemento, provocam um deslocamento que tem como efeito a impulsão para baixo dessas partículas maiores. A compreensão desse universo cartesiano requer, portanto, a consideração das leis do movimento que contêm a explicação a respeito de como se dá a comunicação do movimento entre as partes da matéria que compõem o mundo. Aidentificação entre matéria e extensão e a negação do vazio promovidas por Descartes requerem que se leve em conta a interação que ocorre entre os corpos, ou seja, a determinação do movimento de um corpo está ligada à consideração da resistência que oferecem os corpos que o rodeiam. Dessa forma, a gravidade torna-se consequência da ação da matéria celeste sobre um corpo. O movimento extremamente rápido das partes dessa matéria e a pressão exercida por ela no universo puxam os cor-

\footnotetext{
4 Daí toda a consideração sobre o assunto que se encontra na carta a Mersenne, de 13.7.1638, que tem como título: "Exame da questão: saber se um corpo pesa mais ou menos estando próximo do centro da Terra do que estando afastado" (AT, 2, p. 222-45).

5 Elementos (corpúsculos) que compõem o universo cartesiano: (1) partículas muito agitadas que se dividem, em uma infinidade de partículas que preenchem todos os vãos encontrados ao redor dos corpos do Sol e das estrelas fixas; (2) matéria cujas partes são redondas e menores em relação aos corpos que vemos sobre a Terra e podem ser divididas em outras menores (céus); (3) partes da matéria que são mais difíceis de serem movidas do que as precedentes, por causa de seu tamanho e figura (Terra).
} 
pos para o centro da Terra, respeitando a lei da natureza que estipula a perseverança dos corpos em seu movimento retilíneo (cf. AT, 11, p. 72-80; 9, p. 211-1).

Na explicação concernente às máquinas simples, Descartes, como já foi afirmado, considera a proporção entre deslocamentos, tomando por base a variação existente entre a força e a resistência. A gravidade, tal como se encontra caracterizada na cosmologia física, ou seja, como ação da matéria sutil do céu sobre os corpos, não desempenha papel algum na estática desenvolvida pelo filósofo. Vejamos como ele define gravidade na carta a Mersenne de 13 de julho de 1638, ao tratar da estática: gravidade é

(...) a força pela qual ele [o corpo] tende a descer em linha reta, estando em nosso ar comum a certa distância do centro da Terra e não sendo nem impelido nem detido por nenhum outro corpo e, por fim, não tendo ainda começado a mover-se (AT, 2, p. 226-7).

Descartes adota um tratamento matemático que toma como noção básica para seu desenvolvimento uma suposição ${ }^{6}$ que só tem função nesse âmbito. Em outras palavras, a caracterização que Descartes faz de gravidade absoluta, válida para a explicação matemática da estática, considera o corpo em condições bem específicas, ${ }^{7}$ de tal forma que nele não é considerada a ação da matéria sutil celeste, ou seja, não recebe o mesmo tratamento que se encontra na explicação físico-cosmológica, na qual a quantidade de movimento tem um papel importante. No campo da estática, ao partir de suposições como a invariância da gravidade absoluta, Descartes procura demonstrar que a gravidade relativa ${ }^{\mathbf{8}}$ dos corpos duros é menor quando eles se aproximam do centro da Terra e, com isso, defende a variação do centro de gravidade dos corpos: o centro de gravidade está relacionado com a ação da matéria sutil e com o estado de movimento do corpo (cf. AT, 2, p. 227-8). Ao tomar a balança como exemplo, o autor mostra que quanto mais afastadas do centro da Terra estiverem as partes dos corpos, menos pesarão e, quanto mais próximas, mais pesadas serão. Essa afirmação está pautada naquele prin-

6 Como fazem os astrônomos, segundo ele próprio afirma (cf. AT, 2, p. 227).

7 "Eu digo em nosso ar comum, porque se ele [corpo] estiver em um ar mais sutil ou mais denso (grossier), é certo que ele será um pouco mais ou menos pesado. Eu o coloco a certa distância da Terra, para que ela seja tomada como regra para os demais. Por fim, digo que ele não deve de forma alguma ser impelido ou detido, nem ter começado a mover-se, por que todas essas coisas podem mudar a força pela qual ele tende a descer" (AT, 2, p. 226).

8 “(...) a força que é preciso empregar para detê-lo [um corpo] e impedir que desça, quando se encontra em certa posição, deve ser medida pelo início do movimento a ser produzido pela potência que o sustenta, tanto para erguêlo como para acompanhá-lo, se ele descer" (AT, 2, p. 229). Cf. Garber, 2002. 
cípio enunciado na carta a Huygens, de 5 de outubro de 1637 , que deu origem ao texto que ficou conhecido como Tratado de mecânica.

Para Descartes, a questão concernente à gravidade é "puramente de fato" (AT, 2, p. 224), envolvendo a ação da matéria celeste que se dá de forma variável, pois aí deve ser considerada a velocidade dos corpos sobre os quais essa ação é exercida. Além disso, a determinação da gravidade, enquanto questão de fato, necessita da construção de uma experiência, o que não parece ser viável, uma vez que as experiências não ultrapassarão as condições de nosso ar, não abrangendo, dessa forma, tudo o que vai muito além ou muito abaixo dele. Assim, a compreensão da gravidade, que desempenha papel fundamental na estática, passa necessariamente pela compreensão de "todo o sistema do mundo", em outras palavras, todos os princípios que regem os fenômenos e compõem a física cartesiana. Somente depois da explicação de todo esse conjunto, será possível voltar-se para a dinâmica, na qual a noção de velocidade poderá ser devidamente apreendida.

Uma vez tendo estabelecido a vinculação entre as mecânicas e as leis da natureza, o filósofo aponta a necessidade de compreender o movimento dos corpos, que é uma noção fundamental de sua física, ao lado da identificação entre matéria e extensão. Nos Princípios de filosofia, o movimento é caracterizado como "o transporte de uma parte da matéria ou de um corpo da proximidade daqueles que lhes são imediatamente contíguos - e que consideramos em repouso - para a proximidade de outros" (AT, 8, p. $5^{3-4 ;}$, p. p6). Note-se que essa definição requer o estabelecimento pelo pensamento de um ponto de referência, a partir do qual possa ser compreendido o movimento local. Mas a causa primeira do movimento será atribuída a Deus, que fixa a sua quantidade. Assim, com base na imutabilidade divina, é afirmado o princípio da conservação da quantidade de movimento (cf. AT, 8, p. 61-2; 9, p. 83-4), que norteará as três leis da natureza e as regras do choque expostas logo em seguida (cf. AT, 8, p. 62-5, 68-7०; 9, p. 84-7, 89-9o). Descartes, a partir do critério de clareza e distinção, constrói sua física com base nas idéias matemáticas existentes no entendimento e nas verdades eternas criadas por Deus, às quais se seguem as leis que, por sua vez, possibilitarão a dedução de outras regras, sempre pautadas no referido critério, e que constituem "os princípios da geometria e das mecânicas" (AT, 8, p. 325-6; 9, p. 321-2).

Na imagem bastante conhecida que consta na carta-prefácio à tradução francesa dos Princípios de filosofia, e que representa a árvore da filosofia, o filósofo remete a um dos três principais ramos das ciências como sendo a mecânica. A mecânica encontra 
sua fundamentação nas leis que regem a física (que depende da metafísica), entendida como a ciência que trata do movimento e dos corpos. Ao constituir-se como uma das ramificações da física, a mecânica fica ligada a essa ciência e, ao mesmo tempo, operase uma distinção entre a física e as ciências que se voltam para as aplicações práticas, dentre as quais se situam as mecânicas. Vemos que nos Princípios não ocorre nenhuma referência ao princípio que está na base da construção de máquinas e, portanto, nenhum desenvolvimento das mecânicas (tratamento existente apenas na correspondência). Trata-se, pois, de um projeto inacabado, daí essa ausência. Na exposição do conteúdo das quatro partes dos Princípios, o autor refere-se ao que resta ainda a fazer da seguinte maneira:

Mas, para levar essa intenção até o fim, eu deveria em seguida explicar da mesma maneira a natureza de cada um dos outros corpos mais particulares que estão sobre a Terra, a saber, dos minerais, das plantas, dos animais e principalmente do homem. Depois, enfim, tratar com exatidão da medicina, da moral e das mecânicas. É o que seria preciso que eu fizesse para dar aos homens um corpo de filosofia completo (AT, 9, p. 17).

Nesse trecho, indicando o caráter inacabado de seu projeto, o filósofo refere-se às mecânicas, a exemplo do que ocorre ao longo de sua correspondência com Huygens e Mersenne. As mecânicas vinculam-se a aplicações, à teoria das máquinas, que obviamente se valem do princípio da estática, além das regras enunciadas no 0 mundo e nos Princípios, enquanto a mecânica vincula-se à física, ao corpo teórico, como uma de suas partes. Toda essa vinculação está coerente com a defesa da unidade do conhecimento, além de confirmar uma afirmação que se encontra na sexta parte do Discurso do método (1637), segundo a qual:

tão logo adquiri algumas noções gerais relativas à física e, começando a comproválas em diversas dificuldades particulares, ${ }^{9}$ observei até onde podiam conduzir e o quanto diferem dos princípios que foram utilizados até o presente, [...] elas me fizeram ver que é possível chegar a conhecimentos que sejam muito úteis à vida, e que, em vez dessa filosofia especulativa que se ensina nas escolas, pode-se encontrar uma outra prática (AT, 6, p. 61).

9 Dificuldades estas que remetem à questão do polimento das lentes e envolvem a necessidade de construção de máquinas para esse fim, como foi mencionado a respeito de sua correspondência com Ferrier. 
Os tratados de mecânica referidos por Descartes estão vinculados à concepção de mecânica como uma ramificação da matemática, e o tratamento aí dado distanciase do uso voltado para "explorar a natureza do mundo físico". A estrutura dos tratados de mecânica indica ainda esse vínculo com a matemática, pois aí encontramos definições, suposições, enfim, mais abstrações do que a realidade física. Lembremos da resposta de Descartes a Fromondus, em carta de 3 de outubro de 1637, por meio de Plempius, na qual afirma ser a mecânica uma parte da "verdadeira física" que, por ter sido negligenciada pelos "cultores da filosofia vulgar", conservou-se como a "parte mais verdadeira e menos corrompida da filosofia" por ter ficado no âmbito dos matemáti$\cos (\mathrm{AT}, 1$, p. 421). Em outras palavras, nessa carta, há referência à mecânica que está em uso como parte da física que ficou nas mãos dos matemáticos, ausente, portanto, da filosofia natural (cf. Gabbey, 1993).

Nicolas-Joseph Poisson, autor das Observações sobre as mecânicas do senhor Descartes, afirma que as mecânicas, das quais Descartes se serve, têm uma ligação com as matemáticas, no que concerne aos princípios que lhe são emprestados, e com a física, pelo conhecimento dos corpos e dos movimentos. Essa vinculação está posta na resposta enviada à crítica feita por Fromondus à física cartesiana por considerar figuras, grandezas, posições e movimentos das partes como sendo a mecânica, constituindose, assim, de uma forma muito grosseira. Para Descartes, as razões aceitas devem ter caráter matemático e evidente, e as conclusões devem ser apoiadas em experiências certas (cf. AT, 1, p. 420-1). Em sua apresentação da explicação das máquinas de Descartes, Poisson deixa bem claro o que entende por mecânica, ao informar que ela vai além da construção de máquinas e do conhecimento de suas partes, e inclui o céu e o corpo humano, enquanto compostos por partes dotadas de movimento:

sob esse termo estão incluídas todas as diferentes maneiras pelas quais um corpo se move em relação a certas leis da natureza que jamais podem ser contestadas. Assim, pode-se considerar todo o céu como um corpo composto de várias partes que se correspondem e têm ligações umas com as outras por certos movimentos comunicados entre si; a consideração desse movimento, da disposição, figura e situação de suas partes forma toda a ciência mecânica cujos princípios são tão infalíveis como as demonstrações bem aceitas (Descartes, 1668, p. 18). 
A breve explicação dos instrumentos para erguer cargas, que se encontra na carta a Huygens de 1637 , remete a outros textos de Descartes que merecem ser mencionados a respeito da construção de outras máquinas.
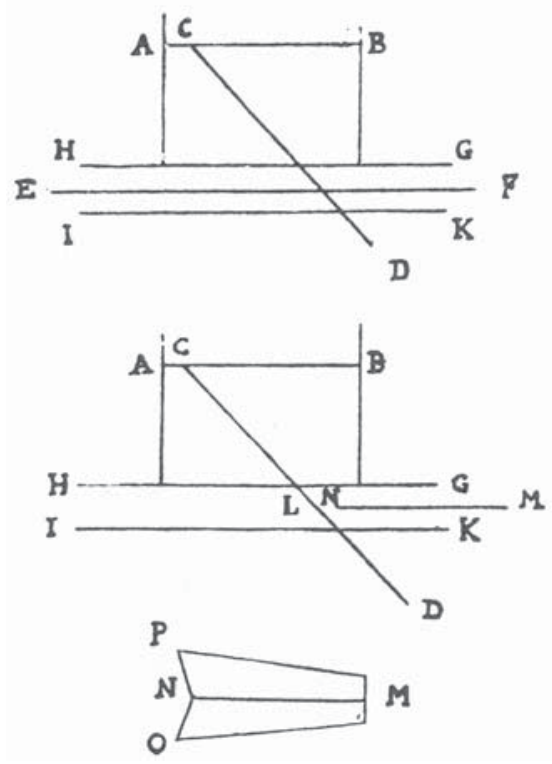

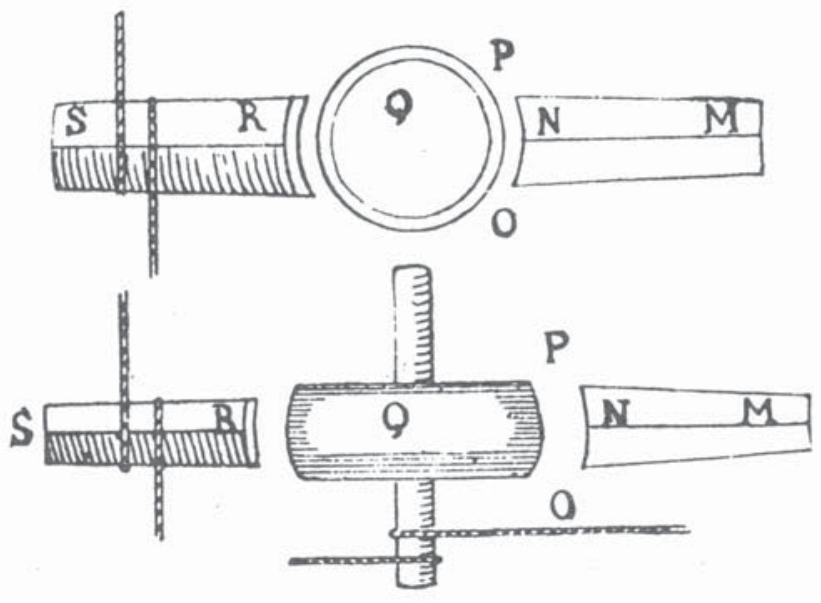

Figura 2. Duas ilustrações da carta de Descartes a Ferrier de 8 out. 1629. À esquerda, o esquema empregado por Descartes para descrever a máquina de fabricar lâminas de ferro e aço temperado, para serem empregadas depois, por meio do mecanismo ilustrado à direita, para o polimento do vidro.

No início deste trabalho foi afirmado que, em 1629, Descartes se corresponde com o artesão parisiense Jean Ferrier a respeito da construção de uma máquina para polir lentes, mais especificamente, lentes hiperbólicas. Na carta de 8 de outubro de 1629 (AT, 1, p. 32-7), encontra-se a proposta de Descartes com uma descrição da composição dessa máquina e ilustrações de suas partes fundamentais, bem como a indicação do tipo de material que deveria ser empregado em sua construção. Em sua resposta (AT, 1, p. 38-52), Ferrier expõe sua compreensão da explicação enviada por Descartes e acrescenta algumas questões. Dentre elas, as concernentes ao material mais adequado a ser utilizado nas peças dessa máquina apresentam algumas sugestões à proposta original, justificando o uso de outros materiais. Ferrier também propõe alguns ajustes na posição das peças de forma a possibilitar o movimento de todas para atingir o fim de- 
sejado. Essa carta de Ferrier é rica em ilustrações que serão retomadas e acrescidas de detalhes na resposta de Descartes, em 13 de novembro de 1629 (cf. AT, 1, p. 53-69). Nesta última resposta de Descartes (cf. Gaukroger, 1999, p. 244-8), são encontrados detalhes da composição da máquina com recomendações a serem seguidas para evitar qualquer trepidação que possa prejudicar o polimento das lentes e com ilustrações um pouco mais minuciosas, incluindo uma que contém a máquina inteira e que será retomada, em 1637, no décimo discurso da Dióptrica (cf. AT, 6, p. 211-27).
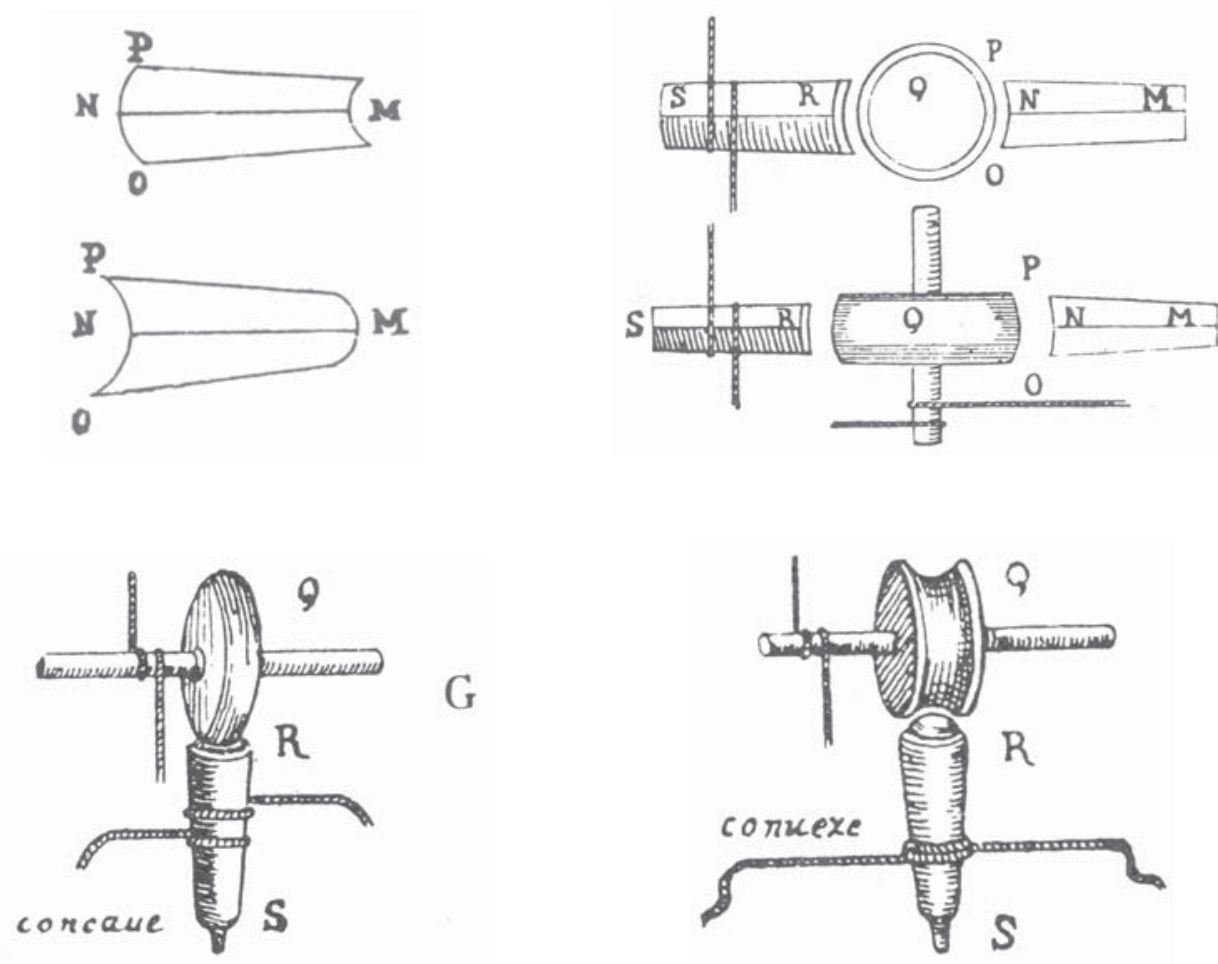

Figura 3. Quatro ilustrações da carta resposta de Ferrier a Descartes de 26 out. 1629. As superiores são usadas para explicar as dificuldades com relação ao desenho proposto por Descartes. As inferiores ilustram propostas de Ferrier de mecanismos para o polimento de lentes côncavas e convexas.

A preocupação concernente ao polimento das lentes hiperbólicas, que envolve a dificuldade em obter imagens sem distorções por meio da mensuração da refração da luz, está ligada à construção de aparelhos ópticos. Essa mensuração, por sua vez, requer a construção de um instrumento específico que auxilie a determinar a proporção 
exigida para tal fim (cf. AT, 6, p. 212-3), a partir da qual possa ser traçada a hipérbole com um compasso. A partir dessa determinação, Descartes expõe em detalhes como deve ser construída a máquina para polir as lentes. A importância desse aparato está no fato de a roda e o torno que o compõem poderem cortar e polir as lentes por meio de determinados movimentos, levando a bons resultados, o que só casualmente poderia ser atingido com a prática então em uso, que era manual (cf. AT, 6, p. 224).

A retomada da explicação sobre a montagem da máquina para polir lentes hiperbólicas no discurso intitulado "Sobre a forma de cortar as lentes" da Dióptrica segue justamente o discurso sobre "A descrição das lunetas" (cf. AT, 6, p. 196-211). Neste último texto, Descartes oferece uma descrição da composição das lunetas, explicando, além do tamanho e espessura necessários para as lentes, como devem ser talhadas as superfícies das duas lentes hiperbólicas para que estejam adequadas a todos os tipos de visão, de forma que seja possível ver objetos muito distantes por meio do aumento ou diminuição do tubo que as contém.

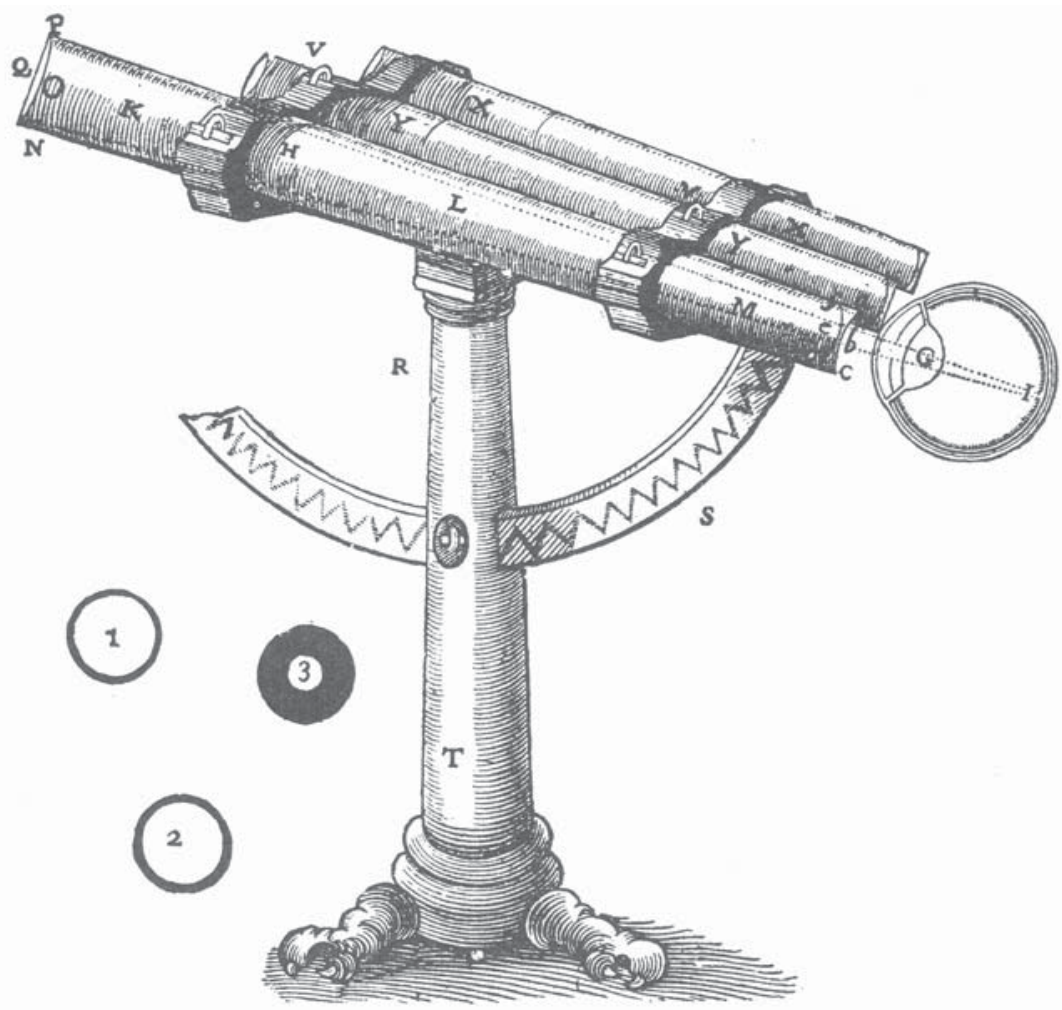

Figura 4. No Discurso Ix da Dióptrica, Descartes emprega esta ilustração em sua explicação do efeito do aumento ou da diminuição do tubo da luneta. 
Os dois discursos que encerram a Dióptrica apontam para a preocupação do autor com a aplicação do conhecimento nela exposto, como indicado no prefácio aos ensaios, intitulado Discurso do método para bem conduzir sua razão e procurar a verdade nas ciências, mencionado logo no início deste trabalho. Essa preocupação, atrelada ao interesse em tornar conhecido o funcionamento das máquinas, sejam elas simples ou complexas, está presente na obra científica cartesiana. As máquinas também aí estão presentes a título de comparação. No Discurso do método, a referência ao tratado não publicado - 0 mundo, incluindo $O$ homem - remete à comparação entre o corpo dos seres vivos e um autômato, uma máquina:

O que não parecerá de forma alguma estranho àqueles que, sabendo quantos diversos autômatos ou máquinas móveis a indústria dos homens pode fazer empregando pouquíssimas peças, em comparação com a grande quantidade de ossos, de músculos, de nervos, de artérias, de veias e de todas as outras partes existentes no corpo de cada animal, considerarão esse corpo como uma máquina que, tendo sido feita pelas mãos de Deus, é incomparavelmente melhor ordenada e contém em si movimentos mais admiráveis do que qualquer uma daquelas que podem ser inventadas pelos homens (AT, 6, p. 55-6).

É bastante conhecido o emprego, no tratado 0 homem, de esquemas mecânicos de autômatos hidráulicos comumente vistos nos jardins reais. Retomando os trabalhos de Géneviève Rodis-Lewis (1956) e de Jurgis Baltrušatis (1984), nota-se que os exemplos utilizados por Descartes remetem aos de um engenheiro e arquiteto francês, Salomon de Caus. Mas não há como afirmar que os problemas contidos no livro A razão das forças motrizes com diversas máquinas tão úteis quanto divertidas, junto às quais foram colocados desenhos de grutas e de fontes (Caus, 1615) possam ter exercido influência sobre Descartes nos campos da física e da fisiologia. De qualquer forma, não deixa de ser curiosa a semelhança entre alguns problemas propostos por Caus e a interpretação cartesiana. A obra de Salomon de Caus é composta por três livros. Toma como ponto de partida a definição dos quatro elementos, em seguida, passa a expor os teoremas, apresenta os problemas, a composição das máquinas, os desenhos de fontes e grutas até chegar às máquinas hidráulicas e à fabricação de órgãos musicais. Todo esse conteúdo está fartamente ilustrado e acompanhado por esquemas explicativos. O que chama a atenção são os problemas referentes a jogos e à fabricação de órgãos. Dentre esses problemas, destaca-se o de número xxvıı, do livro ı, sobre o funcionamento da máquina que representa Netuno e provoca um jato de água ao girar com outras figuras, pois ele remete à comparação que Descartes estabelece entre o maquinário de uma fonte e o corpo humano: nervos são comparados aos tubos das máquinas das fontes; tendões e 
músculos são comparados a engenhos e a engrenagens que servem ao movimento; os espíritos animais, à água; o coração, à fonte; as concavidades do cérebro, às aberturas que distribuem a água (espíritos); a respiração e as ações comuns que dependem dos espíritos, aos movimentos de um relógio ou de um moinho; os objetos externos que estimulam os nervos, às pessoas que provocam os movimentos nas grutas da fonte; a alma racional com sede no cérebro, ao encarregado da fonte - situado na confluência dos tubos - que controla todos os movimentos da máquina. No livro is, encontram-se dois problemas que também podem ser relacionados à concepção cartesiana do corpo dos seres vivos. O de número xvi apresenta uma figura que representa um rio com grutas escavadas em seu interior, e o de número xvir mostra uma gruta (a de Orfeu) que pode ser formada dentro da figura anterior. Ora, essas imagens acabam por remeter, justamente, à descrição que Descartes fornece do interior do corpo com suas concavidades, seus ventrículos e o deslocamento dos espíritos animais por um mecanismo hidráulico. Além disso, Descartes, ao explicar o curso dos espíritos animais a partir dos ventrículos do cérebro para os nervos e músculos, toma como modelo os órgãos das igrejas:

Se vós já tivésseis a curiosidade de ver de perto os órgãos de nossas igrejas, vós saberíeis como, neles, os foles impulsionam o ar em certos receptáculos que, parece-me, são chamados, nessa ocasião, de porta-ventos, e como esse ar entra nos tubos, ora em uns ora em outros, segundo as diversas maneiras pelas quais o organista move seus dedos sobre o teclado. Ora, vós podeis, aqui, conceber que o coração e as artérias, que impelem os espíritos animais para as concavidades do cérebro de nossa máquina, são como o fole desses órgãos que impelem o ar nos porta-ventos (AT, 11, p. 165).

Essa imagem, por sua vez, remete ao livro iı da obra de Salomon de Caus, no qual se encontra uma detalhada descrição da estrutura dos órgãos e de tudo o que é necessário para sua fabricação.

Essa redução a um esquema conhecido, em outras palavras, esse recurso à analogia (cf. Cahné, 1978, p. 201) é encontrado ao longo de toda a obra cartesiana e não poderia estar ausente na explicação do ser vivo: a explicação sobre o funcionamento do corpo humano fica submetida ao modelo das máquinas hidráulicas, cujo funcionamento é amplamente dominado pelo homem. Essa aproximação é possibilitada, uma vez que a diferença entre máquinas naturais e artificiais não se encontra nos princípios de seus movimentos, mas sim na dimensão, na quantidade e na capacidade dos órgãos presentes nas primeiras. Assim, só devem ser considerados a figura e o movimento de suas partes. É desta maneira que são encontradas comparações diferenciadas no trata- 
mento do corpo, aplicadas a determinados fins: relógios (autonomia e regularidade do funcionamento do corpo), fontes, moinhos, órgãos das igrejas (circulação do sangue e dos espíritos) (cf. Duschesneau, 1998, p. 70). Nesse quadro, os modelos das máquinas simples, descritas na carta a Huygens, encontram o seu lugar na explicação sobre o processo de sensação e de movimento dos músculos, como lembra Duchesneau, ao lado de modelos mais complexos presentes na explicação do batimento cardíaco, por exemplo (cf. Duschesneau, 1998, p. 71).

Dessa forma, as mecânicas possibilitam ao espírito a compreensão, a partir dos princípios nelas expostos, de como se dá a ação recíproca dos componentes do universo. O princípio mencionado, nas cartas a Huygens e a Mersenne, que fundamenta a construção de máquinas e, portanto, compõe a base das mecânicas, está atrelado à utilidade apontada por Descartes em sua defesa de uma filosofia prática, segundo a qual as ciências devem possibilitar ao homem tornar-se como mestre e possuidor da natureza. Esse "tornar-se como", afirmado por Descartes, configura-se dentro de um quadro no qual o homem aparece com o domínio de técnicas que possibilitam o uso dos recursos que são oferecidos pela natureza que, por sua vez, obedece apenas às leis imutáveis provenientes de Deus.@

\section{Marisa Carneiro de Oliveira Franco Donatelli Professora Titular do Departamento de Filosofia, Universidade Estadual de Santa Cruz, Brasil. madonat@uesc.br}

\section{REFERÊNGIAS BIBLIOGRÁFIGAS}

Adam, G. \& Tannery, P. (Ed.). Oeuvres de Descartes. Paris: Vrin/Centre National Du Livre, 1995-1998. $11 \mathrm{v.}$ (AT)

Baltrušatis, J. Anamorphoses ou thaumaturgus opticus. Paris: Flammarion, 1984.

Cahné, H. Descartes et l'analogie. Actes du VIIIe Colloque de Marseille, 1978. p. 199- 203.

CAus, S. Les raisons des forces mouvantes, avec diverses machines tant utiles que puissantes, auxquelles sont adjoints plusieurs dessings de grotes \& fontaines. Francfort: Norton, ${ }_{1615}$.

Descartes, R. Traité de la mechanique. Paris: Charles Angot, 1668.

Duschesneau, F. Les modèles du vivant de Descartes à Leibniz. Paris: Vrin, 1998.

Dunem, P. The origins of statics: the sources of physical theory. Boston: Kluwer Academic Publishers, 1991.

GabBey, A. Descartes' physics and Descartes' mechanics: chicken and egg? In: Voss, S. (Ed.). Essays on the philosophy and science of René Descartes. New York: Oxford University Press, 1993. p. 311-23.

Garber, D. A different Descartes: Descartes and the program for a mathematical physics in his correspondence. In: Gaukroger, S. (Ed.). Descartes' system of natural philosophy. Cambridge: Cambridge University Press, 2002. p. 113-30. 
Gaukroger, S. Descartes: uma biografia intelectual. Rio de Janeiro: Edurej/Contraponto, 1999.

(Ed.). Descartes' system of natural philosophy. Cambridge: Cambridge University Press, 2002.

Kobayashi, M. A filosofia natural de Descartes. Lisboa: Instituto Piaget, 1996.

Rodis-Lewis, G. Machineries et perspectives curieuses dans leurs rapports avec le cartésianisme. XVIIe Siècle, 32, p. 461-74, $195^{6 .}$

Voss, S. (Ed.). Essays on the philosophy and science of René Descartes. New York: Oxford University Press, 1993.

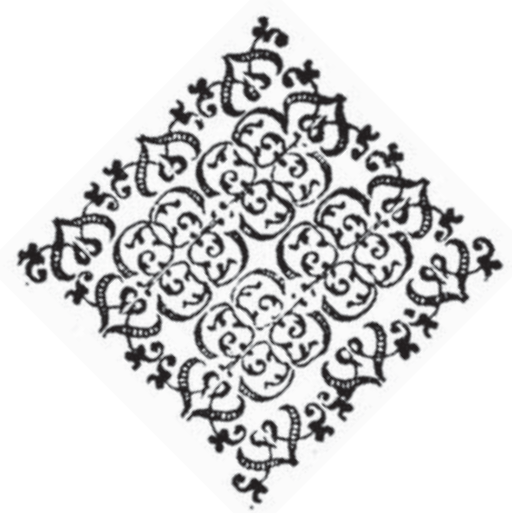

